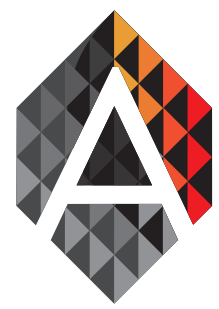

ADCAIJ: Advances in Distributed Computing and Artificial Intelligence Journal Regular Issue, Vol. 8 N. 1 (2019), 27-36

eISSN: $2255-2863$

DOI: http://dx.doi.org/10.14201/ADCAIJ2019812736

\title{
Multi-Agent Vehicle Share System
}

\author{
Adrián Valera Román, Diego Mateos Matilla, \\ Eduardo Oliva Rubio, and Álvaro Paule Pereda
}

adrianvalrom@gmail.com,id00715479@usal.es, Eduoliva@usal.es, alvaro.paule33@usal.es

University of Salamanca

\begin{tabular}{ll} 
KEYWORD & ABSTRACT \\
\hline Multi-Agent; & A multi-agent system is proposed that simulates a network of vehicle rental stations \\
JADE; & in a city. The paper studies the relationship between the agents and the client, anal- \\
Vehicle share & yses the casuistry associated with possible problems that may be encountered in the \\
system; & absence of transport in a given stop, as well as the decisions that could be taken by \\
ecological & the interested party. Subsequently, an architecture capable of being scalable in terms \\
& of functionalities and the number of agents involved in it will be proposed. The aim \\
& of this paper is to revise the original paper, which is more focused on the possibility \\
& of studying a particular city, raising and solving the problems associated with public \\
vehicle sharing services.
\end{tabular}

\section{Introduction}

Bicycles are one of the most efficient means of urban transport; functionally, economically and ecologically, for short and medium distance journeys, as well as being an indirect way of doing good physical exercise. It is therefore not surprising that the emergence of various bicycle sharing services has spread throughout western cities, as well as eastern China, South Korea and Japan, especially in Europe and the most populated areas of northeast Asia where security and the topology of urban space make up the ideal space for these proposals, as opposed to what we might find in cities in the United States, much more relaxed in space, or in Latin America, with less perception of street security and less confidence in the rule of law. This type of service has gained a great attraction due to its low cost and versatility of use, since the new infrastructure allows it: several stations distributed throughout the city. These have evolved over time, and today it is essential to analyze various approaches to the implementation, maintenance and improvement of bicycle sharing systems (Gebhard and Noland, 2013).

It can therefore be observed that, from the previous study to the implementation and operation of stations, the observation and analysis of user behavior both individually and collectively as well as the reactivity of all these elements with the environment in which they move, and on which they are closely dependent, are intimately related and must be studied as a whole (Patil et al., 2015).

By coming to a good analysis of all these elements, understanding their interdependence, we could allow service feedback, seeking a degree of autonomy that would suit a system that operates in a complex and mobile city, which is in constant evolution. There are numerous variables to take into account when creating and maintaining a software that takes all this into account, especially when operating in a specific city that forces to seek a dynamic approach both in the medium and long term: fashions in the city that affect the demand for vehicles

Adrián Valera Román, Diego Mateos Matilla, Eduardo Oliva Rubio, and Álvaro Paule Pereda Multi-Agent Vehicle Share System
ADCAIJ: Advances in Distributed Computing and Artificial Intelligence Journal Regular Issue, Vol. 8 N. 1 (2019), 27-36 elSSN: 2255-2863 - http://adcaij.usal.es Ediciones Universidad de Salamanca - CC BY NC DC 
or stations, weather, events, routines of use of stations throughout the different days of the week, unforeseen (Pablo Chamoso et al., 2018).

A more theoretical approach is needed before focusing on data collection and consequent long-term decision making: a multi-agent simulation system of the vehicle sharing system will be proposed throughout the article; with two classes of agents: customers and stations. These operate freely and interact with each other allowing the movement of the former along a map of stations as a city: allowing the study of the optimal operation possible. In this way, a first contact with a virtualized network of stations is possible, from which conclusions can be drawn that are closer to the problems we introduced at the beginning (Du et al., 2014). Throughout the article we will look at the types of systems currently in existence, the problems that arise when trying to implement this type of service and finally the multi-agent proposal that is proposed as a means to allow the virtualization of a service of this type operating in real time (ALVES et al., 2015).

In general, bicycle sharing systems have the same premises: Customers take vehicles at a low cost from a station, use it to move around and return it to the same or similar station. This does not expect anything else that there is a bike at the stop you want and should not have some other variable in consideration, is the service that provides the attempt that there is no unsatisfied demand at a stop (Yin et al., 2012).

Peter Midgley (2011) indicates in the following study that these systems can be categorized in 4 generations:

1. First Generation Bike Sharing System: Free bicycles offered that could be taken and left anywhere. Vandalism problems.

2. Second generation: A coin system used at the time of taking the bicycle is added. However, this system is anonymous and remains a security issue.

3. Third generation: Emerging technologies such as GPS, tokens and various electronic solutions are used to solve security problems.

4. Fourth generation: That which is in the process of development, which seeks a better exploitation of technological innovation and a better implementation of information technology.

As we can see, the paradigm evolves towards technological solutions thanks to improved security, advances in technology, and easier access to information acquisition and decision-making capabilities. There is a tendency to offer greater flexibility to the user.

\subsection{Associated Problems}

Currently there are different problems around the implementation of vehicle sharing systems, ranging from problems related to the quality of service to others related to physical factors and the environment in which you want to implement the system.

The main ones are described below:

- Network design problems: i.e. problems related to the initial design of the system considering the distance between the stations and the traffic in them. The number of stations and the number of vehicles in each of them is the main problem, another is also the geographical location of the station. These problems arise not only in the initial design but also after the system has collected information, the design will be updated according to the new data collected (Souza et al., 2017).

- Vehicle reassignment problems: this category focuses on the operational aspect. The stations must be balanced, using a prediction algorithm and a reallocation algorithm to minimize the cost of doing it. This means that if, for example, at a certain time every day a station runs out of vehicles, the system will provide more vehicles to that station.

- Vehicle Shortage Problem: when a user wants to pick up a vehicle from an empty station or return it to a station that is full. To solve this it is tried that the users pick up vehicles of full stations and leave them in the ones that are empty, it is tried to achieve informing the users where they can pick up or leave the vehicle and offering them an advantage if they do it. Another solution would be that when the station occurs it warns about it and that this way the vehicles are reassigned in the moment.

Adrián Valera Román, Diego Mateos Matilla, Eduardo Oliva Rubio, and Álvaro Paule Pereda Multi-Agent Vehicle Share System
ADCAIJ: Advances in Distributed Computing and Artificial Intelligence Journal Regular Issue, Vol. 8 N. 1 (2019), 27-36 eISSN: 2255-2863 - http://adcaij.usal.es Ediciones Universidad de Salamanca - CC BY NC DC 
At the moment we can find numerous works on the prediction of the demand of the station, to solve the problems described above. There are some works that show how to implement prediction models based on time series analysis methods such as the auto-regressive moving average. (Kaltenbrunner et al, 2010). Some researchers started a search to obtain the prediction of the demand for bicycles in the stations, applying algorithms to predict the overall use of bicycle sharing. There are several that present predictive models of the total number of bicycles rented per hour at the system in their work (Patit et al, 2015), but today it is possible to obtain data from the services that can be used to build prediction models for each station and predict the lawsuit. This will make it possible to provide useful information for a new strategy for the reallocation of (Matos et al., 2015). They present an interesting work in which they achieve the two previous objectives: prediction models for each station and a rebalancing algorithm. The data used in this work provided information about the bicycle systems and was related to the trips made in the system.

As we see that problems open up a range of possibilities and problems, it is difficult to solve each of these without a prior holistic and statistical study. To this end, a fourth-generation virtual vehicle sharing system will be proposed that will seek to clarify the associated problems described above: With a modular system of stations with customisable behavior, we will be able to define different circumstances and see how the problems develop in each one of them (Shaheen et al., 2010). This last point is dedicated to the reasons this paper is based on: to achieve a framework that allows experimentation, creativity and flexibility in implementation, the study of the effectiveness of various problem-solving approaches in hypothetical cities and the relationship of stations and vehicles with service users.

\section{Proposal}

A multi-agent system is proposed that runs on the platform for the development of JADE agents, implemented in Java. The different agents will form a public and ecological transport sharing system of a city. Dynamic agents will take the role of users while stationary agents will play the role of Stations on which users will make requests for vehicles. All will be able to manage Vehicle objects: bicycles and electric scooters. They will communicate through messages belonging to a common ontology that they will be able to resolve autonomously with the aim of seeking maximum modularity and independence within the virtual ecosystem.

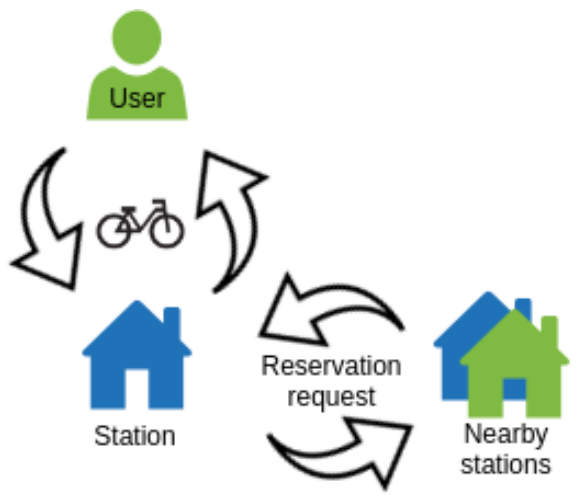

Figure 1: Diagram of communication between agents

In addition, there is a third type of Monitor agent, which will be the only one in charge of representing the actions carried out by the other agents.

Adrián Valera Román, Diego Mateos Matilla, Eduardo Oliva Rubio, and Álvaro Paule Pereda Multi-Agent Vehicle Share System
ADCAIJ: Advances in Distributed Computing and Artificial Intelligence Journal Regular Issue, Vol. 8 N. 1 (2019), 27-36 eISSN: 2255-2863 - http://adcaij.usal.es Ediciones Universidad de Salamanca - CC BY NC DC 


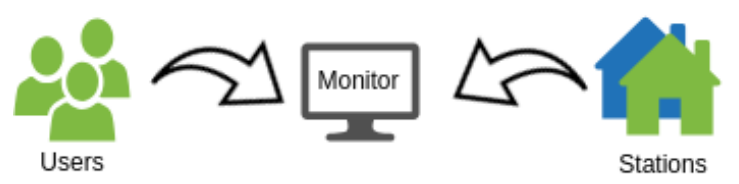

Figure 2: Diagram of notifications to monitor

The main objective to be achieved is high stability, extensibility of characteristics/behaviors and modularity. Achieving this goal, the system can be used to study the problems associated with vehicle sharing systems and obtain data from the observation of the individual behavior of the agents as well as the ecosystem that is formed over time.

The user agents are only interested in travelling to their destination stop with their favorite type of vehicle, they make requests to the stations where they are with the aim of obtaining this vehicle.

The stations, autonomously, are responsible for resolving the request and satisfy the user in the best possible way. In case a stop could not resolve the request would take the decision to communicate with nearby stations to reserve the required vehicle, seeking to satisfy the user in the best possible way. For the ones interested, a class diagram is shown bellow with the main elements that will be instantiated:

\begin{tabular}{|l|}
\hline \multicolumn{1}{|c|}{ Station } \\
\hline + name : String \\
+ vehicles : List < Vehicle> \\
+ stations : Hashtable<String, Integer> \\
+ stationNames : Enumeration
\end{tabular}

\begin{tabular}{|l|}
\hline \multicolumn{1}{|c|}{ Vehicle } \\
\hline - type : String \\
- reserved : String \\
\hline + Vehicle(String) \\
+ getType( : String \\
+ isType(String) : Boolean \\
+ isReserved(): Boolean \\
+ isReserved(String) : Boolean \\
+ stablishReserve(String) : void \\
\hline
\end{tabular}

\begin{tabular}{|l|}
\hline \multicolumn{1}{|c|}{ User } \\
\hline + agentName: String \\
+ vehicle: Vehicle \\
+ desiredVehicle : String \\
+ currentStation : String \\
+ destinationStation : String \\
+ desiredStation : String \\
+ stations : List<String> \\
+ vehicleTypes : List<String> \\
\hline + setup() : void \\
+ stablishCurrentStation() : void \\
+ stablishDestinationStation() : void \\
+ stablishDesiredStation() : void \\
+ getDesiredStation() : String \\
+ getCurrentStation() : String \\
+ getDestinationStation() : String \\
+ arrivedToFinalStation0 : boolean \\
+ stablishDesiredVehicle(String) \\
+ stablishDesiredVehicle() : void \\
+ getDesiredVehicle(0) : String \\
+ hasVehicle() : boolean \\
+ takeVehicle(Vehicle) : void \\
+ getVehicleName() : String \\
+ leaveVehicle() : Vehicle \\
+ goToStation() : void \\
+ waitSomeTime(int) : void \\
+ notifyMonitor0 : void \\
\hline
\end{tabular}

Figure 5: Simplified class diagram

Adrián Valera Román, Diego Mateos Matilla, Eduardo Oliva Rubio, and Álvaro Paule Pereda Multi-Agent Vehicle Share System
ADCAIJ: Advances in Distributed Computing and Artificial Intelligence Journal Regular Issue, Vol. 8 N. 1 (2019), 27-36 eISSN: 2255-2863 - http://adcaij.usal.es Ediciones Universidad de Salamanca - CC BY NC DC 
The following images shows the simplified behavior diagrams of this pair of agents:

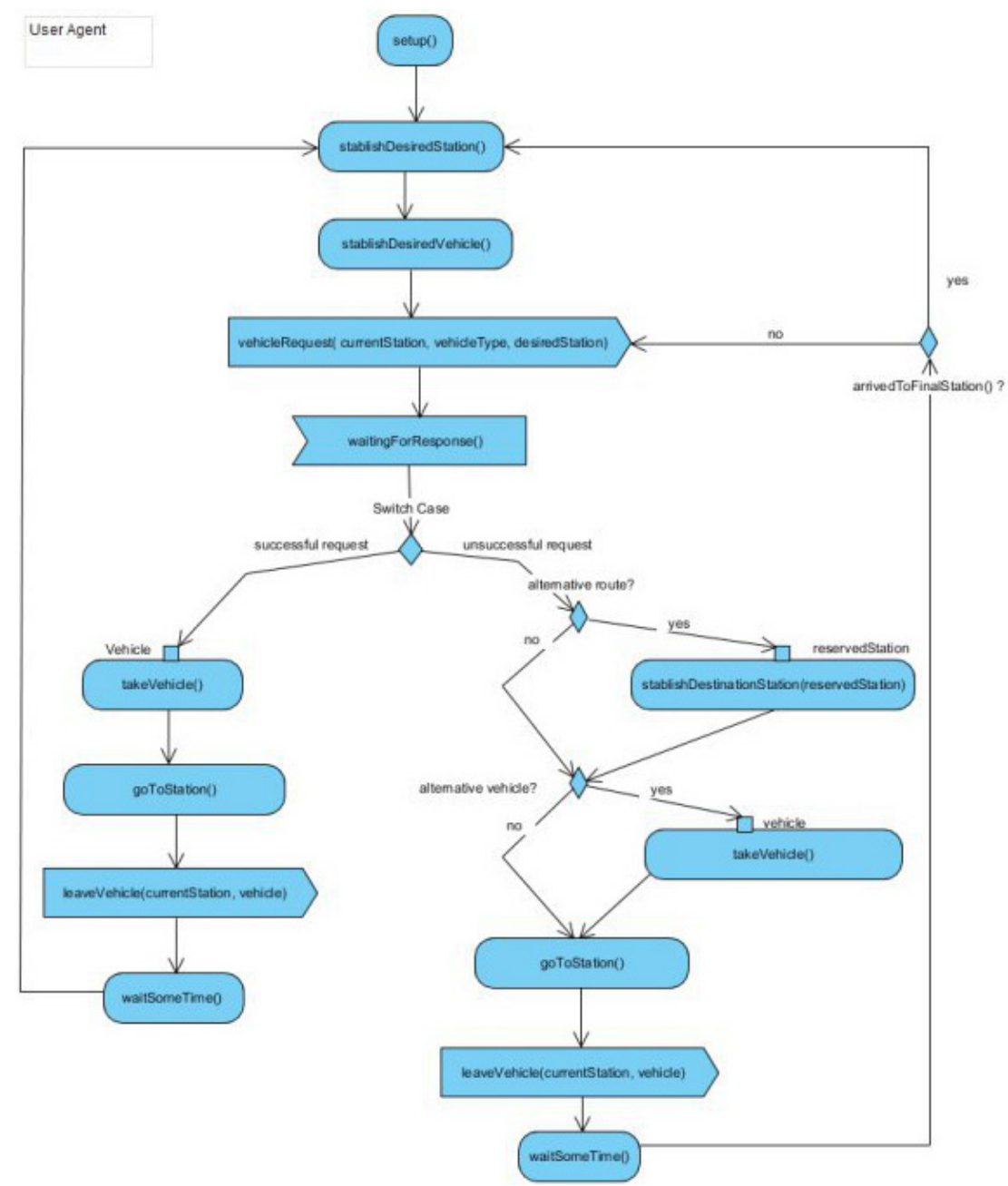

Figure 3: Behavior of User AgentProposal

Adrián Valera Román, Diego Mateos Matilla, Eduardo Oliva Rubio, and Alvaro Paule Pereda Multi-Agent Vehicle Share System
ADCAIJ: Advances in Distributed Computing and Artificial Intelligence Journal Regular Issue, Vol. 8 N. 1 (2019), 27-36 elSSN: 2255-2863 - http://adcaij.usal.es Ediciones Universidad de Salamanca - CC BY NC DC 


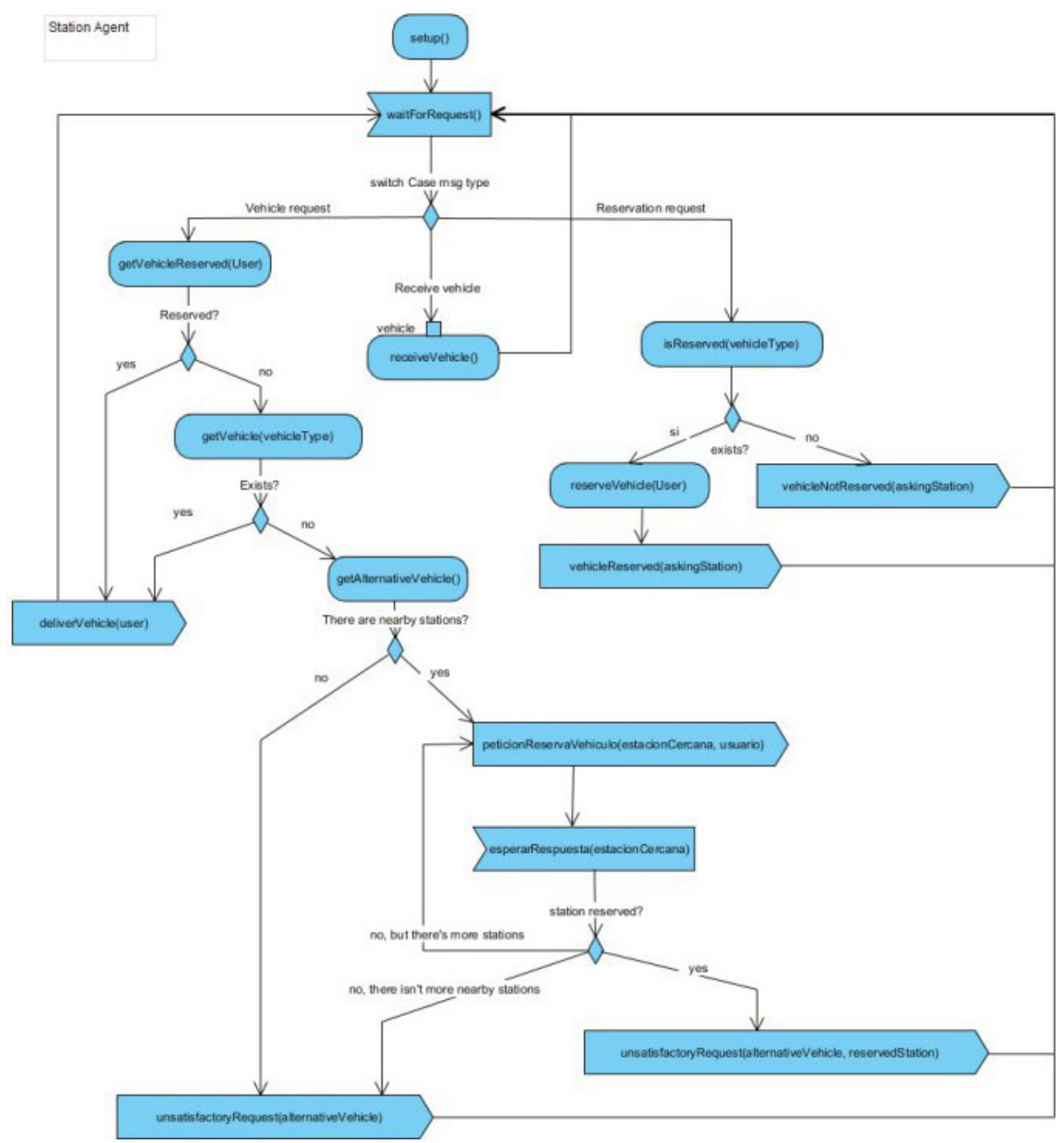

Figure 4: Behavior of Station Agent

In all components of the system are handled mainly Vehicle objects capable of being reserved, this would allow the extensibility to new functions, for example the reserve of vehicles that are being used by a GPS system that could be implemented by another agent. In the terminal of each agent is seen how they handle this type of element, which we can track. All the behaviors will be reflected in the monitor where you see the evolution through time of the decisions taken by the agents, who are responsible for reporting individually their situation when performing an action.

As the system is composed of intelligent agents, autonomous entities that through sensors and actions are able to interact with the environment towards achieving goals, both the user and station agent will have a JADE behavior described above in the cyclic diagrams.

In addition there is a capsule class not represented in the diagram that packs the vehicle, station and various information transmitted between agents, this object is instance with the purpose of sending a message, in particular can come to contain this information: 


\begin{tabular}{ccccc} 
Class & Vehicle & String & String & String \\
Capsule & vehicle & Vehicle type & Station name & User name \\
\hline Example of use: & Vehicle sent & Desired vehicle & User destination station & Reservation username
\end{tabular}

Figure 6. Capsule content

Depending on the type of message, some fields may be ignored or not used if the situation doesn't require it, below we find a table with the messages that allow the intercommunication of agents in wich can be observed the use that is given to the object capsule.

\section{Messages}

\begin{tabular}{llll}
\hline Agent & Performative name & Address & Encapsulated information \\
\hline Monitor: & The monitor only receives STATUS_NOTIFICATION messages from users and stations \\
\hline \multicolumn{5}{l}{ User: } & VEHICLE_REQUEST & \\
\hline & VEHICLE_RETURN & Station & Desired vehicle, desired station \\
\hline & USERSTATUS_NOTIFICATION & Station & Vehicle \\
\hline & & Monitor & - \\
\hline Station: & VEHICLE_DELIVERY & \\
\hline & UNSATISFACTORY_REQUEST & User & Vehicle \\
\hline & VEHICLE_RESERVATION_REQUEST & User & Vehicle, alternative station \\
\hline VEHICLE_RESERVED & Station & Vehicle type, user name \\
\hline VEHICLE_NOT_RESERVED & Station & Void \\
\hline STATIONSTATUS_NOTIFICATION & Monitor & - \\
\hline
\end{tabular}

Figure 7: Message table

\section{Implementation of the proposal}

At the time of implementation, 4 station agents are installed with a series of vehicles and 5 user agents, which operate in a cyclic behavior, moving from one to another choosing routes between stations and vehicles randomly. This implementation as well as the associated code is in github so that anyone can make the tests and modifications it deems appropriate.

Each user makes to the station in which a vehicle request is located, informing of their route. From this moment on, the user is blocked waiting for the station's request before making any other decision.

For its part, the station checks whether it has a vehicle for the user, if so, it would be delivered and would be awaiting a new request. If not, checks if itself can offer an alternative vehicle and if there is a nearby stop that can meet their needs, then makes a reservation request to its adjacent stations and if this is resolved correctly will offer the user, in addition to a possible alternative vehicle, an alternative route.

Adrián Valera Román, Diego Mateos Matilla, Eduardo Oliva Rubio, and Álvaro Paule Pereda Multi-Agent Vehicle Share System
ADCAIJ: Advances in Distributed Computing and Artificial Intelligence Journal Regular Issue, Vol. 8 N. 1 (2019), 27-36 eISSN: 2255-2863 - http://adcaij.usal.es Ediciones Universidad de Salamanca - CC BY NC DC 


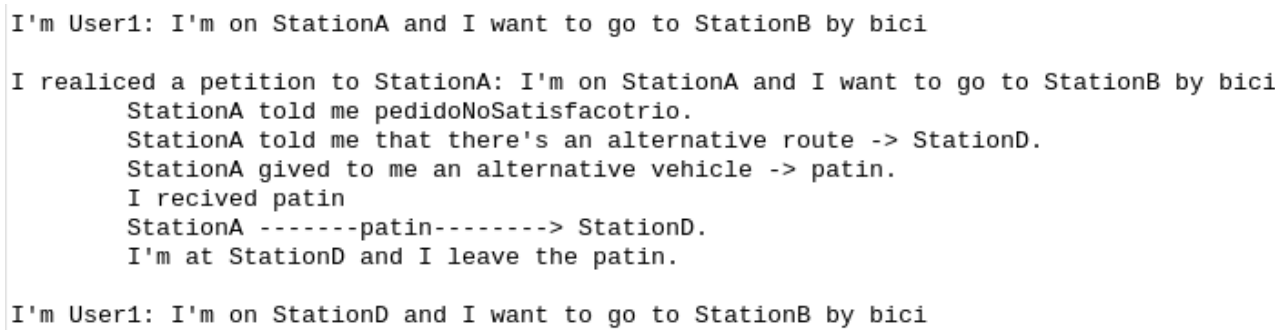

I'm User1: I'm on StationD and I want to go to StationB by bici

Figure 8: User terminal

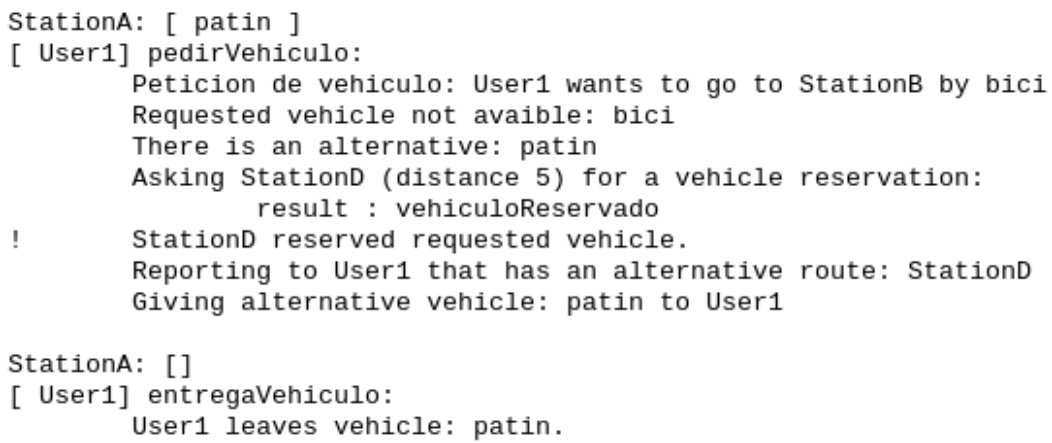

Figure 9: Station terminal

In addition, as everyone informs the monitor of their situation, the monitor will operate independently showing the situation of the system as a whole.

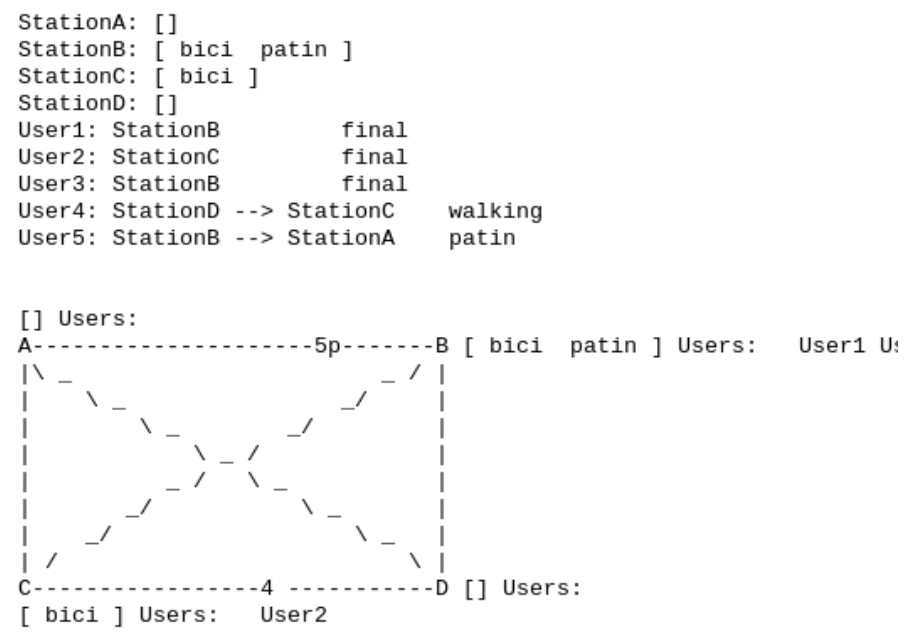

Figure 10: Main terminal

Adrián Valera Román, Diego Mateos Matilla, Eduardo Oliva Rubio, and Álvaro Paule Pereda Multi-Agent Vehicle Share System
ADCAIJ: Advances in Distributed Computing and Artificial Intelligence Journal Regular Issue, Vol. 8 N. 1 (2019), 27-36 eISSN: 2255-2863 - http://adcaij.usal.es Ediciones Universidad de Salamanca - CC BY NC DC 


\section{Discussion and conclusion}

The system allows the adhesion of as many user agents and stations are needed allowing great flexibility when planning virtual cities on which to conduct studies, we can also modify the parameters of all these to perform experiments on an ecosystem.

The modularity of the proposed system and the way of responding to messages allows an easy extensibility, as indicated above would allow for example the inclusion of a new GPS agent to reserve in real time vehicles that are being used by the agent users to improve the efficiency of the requests, for example a demanding user could wait briefly at a stop to the knowledge that another is going to this in order to leave a vehicle. On the other hand, the possibility of extending new functionalities by modifying each agent is left to the air.

The paper on which this study was based was focused more on data collection and problem solving, but in this paper has taken a path focused on the virtualization of these vehicle sharing systems through multi-agent systems, which complements the original paper seeking to allow further study, search for new utilities and as a means to experiment with the proposals that have been exposed. In short, we have a small scalable and modular system that seeks to complement and facilitate the study of vehicle sharing systems. The use of a multi-agent system for the implementation of the proposed system allows the great flexibility seen, to operate each one in an autonomous way each agent individually could be modified without taking too much into account the rest, obtaining a simple and elegant simulation.

Multi-agent systems are used to solve problems that are difficult or impossible to solve for an individual agent or a monolithic system, as well as for the simplification of complex systems that can subdivide their functionality into independent autonomous systems; the freedom they offer us is enormous since the decision making is done at an individual level. Moreover, the fact that each agent can be abstracted as a user or a station facilitates the implementation and adhesion of new features.

\section{References}

Du, J., He, R., and Zhechev, Z., 2014. Forecasting Bike Rental Demand. Gebhard, K., \& Noland, R., 2013. The Impact of Weather Conditions on Capital Bikeshare Trips. TRB 2013 Annual Meeting

Kaltenbrunner, A., Meza, R., Grivolla, J., Codina, J., and Banchs, R., 2010. Urban cycles and mobility patterns: Exploring and predicting trends in a bicycle-based public transport system. Pervasive Mob. Comput. 2010, 6, 455-466.

Alves, Ana Oliveira, Ribeiro, Bernardete., 2015. Consensus-based Approach for Keyword Extraction from Urban Events Collections. ADCAIJ: Advances in Distributed Computing and Artificial Intelligence Journal, Salamanca, v. 4, n. 2, p. 41-60, ISSN 2255-2863.

Matos, D.M., Lopes, B., Bento Dei, C., and Machado, E.R., 2015. An Intelligent Bike-Sharing Rebalancing System, Universidade de Coimbra: Coimbra, Portugal.

Midgley, P., 2011. Bicycle-sharing schemes: Enhancing sustainable mobility in urban areas. Commun. Sustain. Dev., 18, 1-12.

Pablo Chamoso, Alfonso González-Briones, Alberto Rivas, Federico Bueno De Mata, and Juan Manuel Corchado, 2018). The Use of Drones in Spain: Towards a Platform for Controlling UAVs in Urban Environments. Sensors. MDPI.

Patil, A., Musale, K., and Rao, B.P., 2015. Bike share demand prediction using RandomForests. IJISET Int. J. Innov. Sci. Eng. Technol. 2015, 2.

Shaheen, S.A., Guzman, S., and Zhang, H., 2010. Bikesharing in Europe, the Americas, and Asia Past, Present, and Future. Transp. Res. Rec. J. Transp. Res., 2143, 159-167.

Souza De Castro, Lucas Fernando, Vaz Alves, Gleifer, and Pinz Borges, André, 2017. Using trust degree for agents in order to assign spots in a Smart Parking. ADCAIJ: Advances in Distributed Computing and Artificial Intelligence Journal, Salamanca, v. 6, n. 2, 45-55, jun. 2017. ISSN 2255-2863

Yin, Y.-C., Lee, C.-S., and Wong, Y.-P., 2012. Demand Prediction of Bicycle Sharing Systems.

Adrián Valera Román, Diego Mateos Matilla, Eduardo Oliva Rubio, and Álvaro Paule Pereda Multi-Agent Vehicle Share System
ADCAIJ: Advances in Distributed Computing and Artificial Intelligence Journal Regular Issue, Vol. 8 N. 1 (2019), 27-36 elSSN: 2255-2863 - http://adcaij.usal.es Ediciones Universidad de Salamanca - CC BY NC DC 
